Кузьмичев Е. Н., Верхотуров А. Д., Евстигнеев А. И., Дроздов Е. А.

E. N. Kuzmichev, A. D. Verchoturov, A. I. Evstigneev, E. A. Drozdov

ИННОВАЦИОННАЯ ТЕХНОЛОГИЯ ЗАМЕНЫ БУКСОВЫХ НАЛИЧНИКОВ С КОМБИНИРОВАННЫМ ПОКРЫТИЕМ, ФОРМИРУЕМЫМ НА УГЛЕРОДИСТОЙ ОСНОВЕ НАПЛАВКОЙ С ИСПОЛЬЗОВАНИЕМ СПЕЦИАЛЬНОГО ФЛЮСА

\title{
INNOVATIVE PLATES REPLACEMENT TECHNOLOGY WITH THE COMBINED COVERING CREATED ON THE CARBON BASIS USING SPECIAL FLUX WELDING
}

Кузьмичев Евгений Николаевич - кандидат технических наук, доцент кафедры «Локомотивы» Дальневосточного государственного университета путей сообщения (Россия, г. Хабаровск), тел 8 (4212) 407-076. E-mail : accord@festu.khv.ru.

Mr. Kuzmichev Evgenii N. - PhD of Engineering, Associate Professor, Locomotive Department Far Eastern State Transport University (Russia, Khabarovsk). E-mail: e_kuzmichev@mail.ru.

Верхотуров Анатолий Демьянович - доктор технических наук, профессор, главный научный сотрудник Института Водных и экологических проблем ДВО РАН (Россия, г. Хабаровск). E-mail: Verhoturov36@mail.ru.

Anatoly D. Verkhoturov - Doctor of Engineering, Professor, senior researcher at the Institute of Water and Environmental Problems, the Far Eastern Branch of the Russian Academy of Sciences (Russia, Khabarovsk). E-mail: Verhoturov36@mail.ru.

Евстигнеев Алексей Иванович - доктор технических наук, профессор, Заслуженный деятель науки РФ, проректор по научной работе Комсомольского-на-Амуре государственного технического университета (Россия, г. Комсомольск-на-Амуре). E-mail: offise@knastu.ru.

Mr. Alexey I. Evstigneev - Doctor of Engineering, Professor, Provost for Research at Komsomolsk-on-Amur State Technical University, bearer of the little «Honoured Worker of Science and Engineering of Russia» (Russia, Komsomolsk-on-Amur).

Дроздов Евгений Александрович - кандидат технических наук, доцент, кафедры «Подвижной состав железных дорог» Дальневосточного государственного университета путей сообщения (Россия, г. Хабаровск), тел 8 (4212) 407-656. E-mail: vag6@festu.khv.ru.

Mr. Drozdov Evgenii A. - PhD of Engineering, Associate Professor, Rolling Stock Department Far Eastern State Transport University (Russia, Khabarovsk). E-mail: vag6@festu.khv.ru.

Аннотация. Представлены результаты исследований по разработке технологии изготовления биметаллических наличников, представляющих из себя двухслойную пластину с основанием из углеродистой стали. Использование разработанного биметаллического наличника при ремонте буксовых проемов рамы тележки позволяет упростить технологию замены наличника и повысить качество приварки наличника к раме за счет отсутствия дополнительных технологических операций по предварительному подогреву и соблюдения режимов охлаждения, как в случае приварки наличника из стали 60Г.

Summary. The authors present development of bimetallic plates manufacturing techniques. The plates are twolayer plates with the carbon steel. The use of the developed bimetallic plates when repairing jaw opening of a cart frame allows simplifying plate replacement technology and increasing quality of welding the plate to a frame due to lack of additional technological operations of preliminary heating and observance of the cooling modes, as in case of welding of a steel $60 \mathrm{G}$ plate.

Ключевые слова: биметаллические наличники, буксы, технология замены наличника, приварка, предварительный подогрев, режимы охлаждения, износостойкость.

Key words: bimetallic plates, bearing box, plate replacement technology, welding, preliminary heating, cooling modes, durability. 
Кузьмичев Е. Н., ВЕРХотУРов А. Д., ЕвСтиГнЕев А. И., ДРОзДов Е. А.

ИННОВАЦИОННАЯ ТЕХНОЛОГИЯ ЗАМЕНЫ БУКСОВЫХ НАЛИЧНИКОВ С КОМБИНИРОВАННЫМ ПОКРЫТИЕМ,

ФОРМИРУЕМЫМ НА УГЛЕРОДИСТОЙ ОСНОВЕ НАПЛАВКОЙ С ИСПОЛЬЗОВАНИЕМ СПЕЦИАЛЬНОГО ФЛЮСА

\section{УДК 621.791 .75}

\section{Введение}

На сегодняшний день железнодорожный транспорт является одним из основных видов транспорта промышленных предприятий. Его доля в себестоимости товарной продукции варьируется от 6 - $10 \%$ на металлургических заводах до $30-70 \%$ на открытых горных разработках.

В калькуляции себестоимости внутренних железнодорожных перевозок одной из наибольших статей расходов остается «ремонт и содержание подвижного состава». В частности, на эту статью приходится: по тепловозному парку - до 35 \%, по электровозному - до 28 \%, по вагонному до 45 \% общих затрат на эксплуатацию.

В последнее время особую остроту приобретает проблема нарастающего износа деталей локомотивов и вагонов, особенно экипажной части. Высокая стоимость запасных частей и материалов для ремонта приводит к снижению технической готовности деталей подвижного состава.

В то же время до 80 \% деталей, выбраковываемых при ремонте, после восстановления пригодны к дальнейшей эксплуатации. Как правило, потери массы таких деталей не превышают $2 \%$ исходной массы, при этом прочность металла изделий остается на прежнем уровне. По целому ряду наименований наиболее металлоемких и дорогостоящих изделий вторичное их использование значительно больше, чем потребление новых запасных частей. При этом себестоимость восстановления на 65 - 70 \% ниже стоимости новых деталей, а расход материалов в 15 - 20 раз меньше, чем на изготовление.

При ремонте актуальными остаются вопросы повышения ресурса восстановленных деталей за счет формирования качественных характеристик сварочных швов и покрытий посредством их легирования.

Наибольшее применение при ремонте подвижного состава имеют электротермические технологии (сварка и наплавка) - до 46 \% объема сварочно-наплавочных работ при ремонте приходится на электродуговые способы. Из них 63 \% составляет ручная дуговая сварка покрытыми электродами, которая, несмотря на свои недостатки, находит широкое применение при заварке трещин малой протяженности и глубины, устранение которых другими способами или невозможно, или нецелесообразно. При наплавочных работах более прогрессивным способом является автоматическая наплавка под флюсом, доля которой составляет $28 \%$.

В связи с отмеченным, в статье приведены результаты исследований по разработке технологии изготовления биметаллических наличников, представляющих из себя двухслойную пластину с основанием из углеродистой стали и сформированным на её поверхности износостойким рабочим слоем. Формирование покрытий с повышенными физико-механическими и эксплуатационными свойствами производится электротермической наплавкой с применением керамических наплавочных флюсов на основе комплексного использования минерального сырья ДВ региона [1;2].

\section{Методика и материалы}

Проверка работоспособности предлагаемого способа восстановления буксовых наличников рамы тележки железнодорожного подвижного состава осуществлялась в лаборатории сварки ДВГУПС. Наплавку осуществляли аппаратом для автоматической наплавки ТС-17M-1 с источником питания ТДФ-1001, силой тока 200 А проволокой Св-10Г2 диаметром 1,6 мм.

Анализ химического состава полученных сплавов проводили на рентгеновском спектрометре MAKC-GV.

Исследование полученных покрытий буксового наличника на износостойкость осуществлялось в соответствии с ГОСТ 17367-71 «Металлы. Метод испытания на абразивное изнашивание при трении о закрепленные абразивные частицы» на машине трения ИИ-5018 в условиях трения без смазки при нагрузке 200 Н. Материалом эталонного образца служила сталь 40ХН, закаленная в масле (НRC 50-52).

Исследование твердости проводилось в соответствии с ГОСТ 9012-59 «Металлы. Метод измерения твердости по Бринеллю». Испытания на ударную вязкость проводились в соответствии 
с ГОСТ 9454-78 «Металлы. Метод испытания на ударный изгиб при пониженной, комнатной и повышенных температурах». Испытания на прочность при разрыве проводились в соответствии с ГОСТ 1497-84 «Металлы. Методы испытаний на растяжение».

Внутренние дефекты сварных швов определялись ультразвуковым дефектоскопом УД-12П с призматическими и раздельно-совмещенными преобразователями по ГОСТ 14782-86 «Контроль неразрушающий. Соединения сварные. Методы ультразвуковые».

\section{Результаты и обсуждение}

Рама тележек тепловозов ТЭМ2, М62 представляет собой сварно-литую конструкцию, буксы колесных пар в которой размещаются в специальных вырезах (буксовых челюстях). Буксовые челюсти представляют собой стальные отливки, вваренные в раму. К поверхностям трения челюстей электрозаклепками прикреплены сменные наличники из износостойкой стали 60Г, 65Г [3]. Продольные силы передаются буксами через наличники на внутренние поверхности челюстей. Букса и буксовые наличники рамы тележки выполнены с зазором, обеспечивающим лучшее прохождение тележкой кривых участков пути. При движении локомотива за счет этого зазора букса перемещается относительно буксовых наличников. Силы трения, возникающие при взаимном перемещении буксы и буксовых наличников, приводят к износу взаимодействующих поверхностей.

В процессе эксплуатации наличники буксовых вырезов изнашиваются неравномерно как по высоте, так и по ширине. Неравномерный износ буксовых наличников приводит к нарушению ориентации колесных пар в раме тележки и является причиной перекоса колесных пар, возникновения износа поверхности катания бандажей, подреза гребней. Износ наличника определяют путем сравнения толщины изношенной и неизношенной частей. Наличники толщиной мене 4 мм заменяют.

Однако закрепление новых буксовых наличников на буксовом проеме рамы тележки с помощью ручной дуговой сварки не обеспечивает необходимой прочности их соединения, которая является одним из факторов, обеспечивающих безопасность движения поездов.

В тепловозах буксовые наличники рамы тележки выполнены из высокоуглеродистой марганцовистой стали марок 60Г или 65Г и закреплены на рабочих поверхностях буксового проема рамы тележки из низкоуглеродистой стали с помощью электрозаклепок.

Согласно инструкции ЦТ-336 способ восстановления зазора между буксовым узлом и рамой тележки заключается в снятии изношенного буксового наличника механическим путем и замене его на новый буксовый наличник.

После снятия изношенного буксового наличника рабочую поверхность буксового проема рамы тележки подготавливают (зачищают) для установки на нее буксового наличника нормативной толщины. Стали марок 60Г и 65Г являются плохо свариваемыми (эквивалент углерода Сэ = $=0,77)$ и относятся к IV группе свариваемости. Приварка нового наличника должна сопровождаться предварительным и сопутствующим его нагревом для обеспечения высокого качества сварного шва и предотвращения образования закалочных структур, холодных трещин и деформации наличника.

Закрепление буксового наличника на рабочей поверхности буксового проема рамы тележки осуществляют следующим образом. Вначале буксовый наличник нагревают по кромкам до температуры, при которой происходит небольшое их оплавление. Затем каждый буксовый наличник точечно закрепляют струбцинами по всей рабочей поверхности буксового проема рамы тележки для предотвращения его перекоса при дальнейших этапах закрепления. Далее нагретый буксовый наличник приваривают дуговой сваркой по всем кромкам к рабочей поверхности буксового проема рамы тележки, соблюдая порядок наложения швов, согласно рис. 1 [4].

При сварке высокоуглеродистой стали буксового наличника и низкоуглеродистой стали рамы тележки в процессе охлаждения в сварном шве и околошовной зоне происходит образование цементитной фазы и появление значительных собственных внутренних напряжений, вызывающих появление микротрещин. Образование цементита и появление микротрещин в сварном шве делают его хрупким за счет большого содержания углерода в высокоуглеродистой стали [5]. 
Кузьмичев Е. Н., ВЕРХотУРов А. Д., ЕвСтиГнЕев А. И., ДРОзДов Е. А.

ИННОВАЦИОННАЯ ТЕХНОЛОГИЯ ЗАМЕНЫ БУКСОВЫХ НАЛИЧНИКОВ С КОМБИНИРОВАННЫМ ПОКРЫТИЕМ, ФОРМИРУЕМЫМ НА УГЛЕРОДИСТОЙ ОСНОВЕ НАПЛАВКОЙ С ИСПОЛЬЗОВАНИЕМ СПЕЦИАЛЬНОГО ФЛЮСА

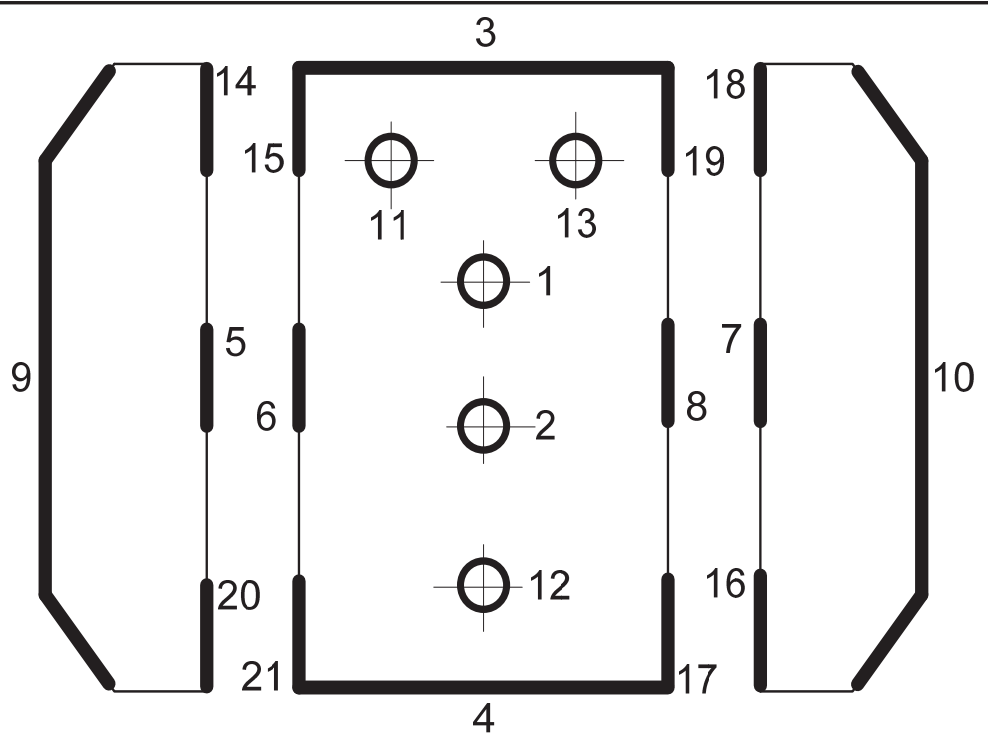

Рис. 1. Последовательность наложения сварных швов при приварке наличников

В процессе эксплуатации тележки действие на буксовый наличник знакопеременных сил трения и вибраций приводит к развитию микротрещин и макротрещин в сварных швах и околошовной зоне. По мере развития трещин появляются разрывы в соединении, которые уменьшают прочность соединения буксового наличника с рамой тележки. Ослабление сварного соединения приводит к смещению буксового наличника относительно рабочей поверхности буксового проема рамы тележки. Это вызывает повышение интенсивности износа и буксового наличника и в крайнем случае приводит к выпадению его из буксового проема.

Недостаток известного способа заключается в низкой прочности соединения замещающего буксового наличника с рабочей поверхностью буксового проема рамы тележки, что обусловлено недостаточным для работы качеством сварного шва за счет плохой свариваемости образующих его высокоуглеродистой и низкоуглеродистой сталей.

Авторами предлагается запатентованный способ восстановления буксовых направляющих рамы тележки тепловоза [6], который повышает работоспособность буксового узла.

Предлагается изготавливать буксовый наличник в виде двухслойной пластины нормативной толщины, один слой которой выполнен из низкоуглеродистой стали, а другой - из высокоуглеродистой стали.

Новый буксовый наличник изготавливают следующим образом. На пластину из низкоуглеродистой стали, содержащей 0,14 - 0,22 \% углерода, обладающей хорошей свариваемостью, например марки Ст3сп, наносят электродуговой наплавкой слой из высокоуглеродистой марганцовистой стали, аналогичной стали марки $60 Г$ или $65 \Gamma$, содержащей $0,57-0,65 \%$ углерода и $0,9-1,1 \%$ марганца.

Для этого пластину из низкоуглеродистой стали выбирают с предельно минимально допустимой толщиной и с габаритами стандартного буксового наличника. Например, для тележки тепловоза ТЭМ2 минимальная толщина пластины принимается 3 мм.

Наплавку слоя из высокоуглеродистой марганцовистой стали на пластину из низкоуглеродистой стали осуществляют под слоем флюса, например, на сварочном автомате низкоуглеродистой сварочной проволокой, содержащей $0,10-0,12 \%$ углерода и $1,8-2,1 \%$ марганца, например Св-10Г2. Для повышения содержания углерода в наплавленном металле до 0,6 - 0,65 \% используют флюс с высоким содержанием углерода, например флюс, состоящий из 93,0 - 95,0 \% типового флюса АН-348В с добавлением в него 5,0 - 7,0 \% графитовой крупки [1].

При наплавке флюс взаимодействует с расплавленным металлом проволоки и пластины, при этом ионы углерода из флюса насыщают расплавленный металл, который после охлаждения содержит 0,57 - 0,65 \% углерода и 0,7 - 1,0 \% марганца. Наплавленный на низкоуглеродистую 
пластину слой является высокоуглеродистым и по химическому составу, а также физическим свойствам идентичным сталям 60Г и $65 \Gamma$.

После наплавки пластину очищают от шлака и механически обрабатывают наплавленный слой до получения пластины толщиной, равной нормативной толщине стандартного буксового наличника. Например, для тележки тепловоза ТЭМ2 толщина готового буксового наличника составляет $6,0-7,0$ мм.

Таким образом, получают новый двухслойный буксовый наличник, один слой которого выполнен из низкоуглеродистой стали, а другой - из высокоуглеродистой износостойкой стали.

Для закрепления каждого замещающего буксового наличника его вначале располагают слоем из низкоуглеродистой стали на рабочей поверхности буксового проема рамы тележки. Таким образом, поверхность буксового проема рамы тележки из низкоуглеродистой стали контактирует с поверхностью замещающего буксового наличника также из низкоуглеродистой стали.

Затем буксовый наличник точечно соединяют струбцинами с рабочей поверхностью буксового проема рамы тележки для предотвращения его перекоса при дальнейших этапах закрепления.

Далее буксовый наличник приваривают дуговой сваркой по всем кромкам к рабочей поверхности буксового проема рамы тележки согласно схеме рис. 1. В результате буксовый проем рамы тележки восстанавливают до нормативных размеров. В связи с тем, что стали буксового проема и изготовленного буксового наличника относятся к I группе свариваемости (эквивалент углерода $C э<0,25)$, создание термического цикла сварки не требуется.

При сварке низкоуглеродистых сталей в процессе охлаждения происходит образование плотного и однородного сварного шва без внутренних напряжений и микротрещин, что обусловлено малым содержанием углерода в свариваемых металлах [6].

Таким образом, достигается повышение прочности соединения буксового наличника с поверхностью буксового проема рамы тележки за счет улучшения качества сварного шва благодаря хорошей свариваемости образующих его низкоуглеродистых сталей.

В результате получают буксовый наличник, хорошо соединенный с рамой тележки и имеющий рабочую поверхность, взаимодействующую с буксой, из высокоуглеродистой износостойкой стали, что соответствует нормативным требованиям.

Получение сварного шва без микротрещин позволяет эксплуатировать буксовый наличник до его предельно допустимого износа. Процесс восстановления может повторяться в течение всего срока службы рамы тележки.

Результаты исследования химического состава и механических свойств наплавленного высокоуглеродистого слоя металла по заявляемому способу и стали марки 60Г приведены в табл. 1.

Таблица 1

Химический состав и механические свойства буксовых наличников

\begin{tabular}{|c|c|c|c|c|c|}
\hline \multirow[b]{2}{*}{$\begin{array}{l}\text { Состав и свойства } \\
\text { высокоуглероди- } \\
\text { стой стали рабочей } \\
\text { поверхности буксо- } \\
\text { вого наличника }\end{array}$} & \multicolumn{3}{|c|}{ Химический состав, \% } & \multicolumn{2}{|c|}{ Механические свойства } \\
\hline & Углерод C & Кремний Si & Марганец Mn & $\begin{array}{c}\text { Твердость } \\
\text { НВ }\end{array}$ & $\begin{array}{c}\text { Износостой- } \\
\text { кость относи- } \\
\text { тельно стали } \\
40 X Н\end{array}$ \\
\hline $\begin{array}{l}\text { Разработанный } \\
\text { буксовый наличник }\end{array}$ & $0,57-0,64$ & $0,23-0,35$ & $0,76-0,94$ & $244-261$ & 1,08 \\
\hline $\begin{array}{l}\text { Буксовый наличник } \\
\text { из стали марки } 60 \Gamma\end{array}$ & $0,57-0,60$ & $0,17-0,35$ & $0,7-1,0$ & $235-275$ & 1,08 \\
\hline
\end{tabular}

Результаты испытания сварных швов, полученных при сварке двух пластин, приведены в табл. 2. В первом примере сварные швы получали при сварке пластин, выполненных из однородного металла - стали марки Ст3 (по заявляемому способу), одна из которых имитирует раму те- 
Кузьмичев Е. Н., ВЕРХотУРов А. Д., ЕвСтиГнЕев А. И., ДРОзДов Е. А.

ИННОВАЦИОННАЯ ТЕХНОЛОГИЯ ЗАМЕНЫ БУКСОВЫХ НАЛИЧНИКОВ С КОМБИНИРОВАННЫМ ПОКРЫТИЕМ,

ФОРМИРУЕМЫМ НА УГЛЕРОДИСТОЙ ОСНОВЕ НАПЛАВКОЙ С ИСПОЛЬЗОВАНИЕМ СПЕЦИАЛЬНОГО ФЛЮСА

лежки, другая - привариваемую сторону буксового наличника. Во втором примере сварные швы получали при сварке пластин, выполненных из разных сталей, одна из которых, выполненная из стали марки Ст3, имитирует раму тележки, другая, выполненная из стали марки 60Г, - буксовый наличник.

Таблица 2

Результаты механических испытаний сварных швов

\begin{tabular}{|l|c|c|c||}
\hline \multirow{2}{*}{$\begin{array}{c}\text { Механические свойства } \\
\text { була шва в месте приварки } \\
\text { букового наличника }\end{array}$} & \multicolumn{3}{|c|}{ Механические свойства сварного соединения } \\
\cline { 2 - 5 } & $\begin{array}{c}\text { Предел прочности } \\
\text { на растяжение } \sigma_{\mathrm{B}} \text {, МПа }\end{array}$ & Угол загиба $\alpha$ & $\begin{array}{c}\text { Ударная вязкость } \alpha_{\mathrm{H}}, \\
\text { КДж/см }\end{array}$ \\
\hline $\begin{array}{l}\text { Предлагаемый способ восста- } \\
\text { новления }\end{array}$ & $430-443$ & $180^{\circ}$, трещин нет & $17-18$ \\
\hline $\begin{array}{l}\text { Существующий способ восста- } \\
\text { новления }\end{array}$ & $360-375$ & $\begin{array}{c}170^{\circ}, \text { трещины } 15 \% \\
\text { от длины шва }\end{array}$ & $14,6-15,5$ \\
\hline
\end{tabular}

Механические испытания сварных швов показали, что прочность швов, полученных с использованием заявляемого способа, по сравнению со сварными швами, полученными с использованием способа прототипа, увеличилась на 13,0 - 17,0 \%.

Увеличение прочности сварного шва, закрепляющего буксовый наличник на раме тележки, повышает уровень безопасности движения поездов.

\section{Выводы}

Разработана технология изготовления биметаллических наличников, представляющих из себя двухслойную пластину с основанием из углеродистой стали марки Ст3 и износостойкого наплавленного слоя, аналогичного стали 60Г.

Использование типовой низкоуглеродистой проволоки марки Св08Г2С позволяет повысить технологичность процесса наплавки. Повышение содержания углерода в наплавленном металле достигается добавлением графитовой крупки в типовой флюс марки АН348В.

Применение разработанного биметаллического наличника при ремонте буксовых проемов рамы тележки позволяет упростить технологию замены наличника и повысить качество приварки наличника к раме. Наличник приваривается к раме основанием из низкоуглеродистой стали, имеющей хорошую свариваемость, что не требует дополнительных технологических операций по предварительному подогреву и соблюдения режимов охлаждения, как в случае приварки наличника из стали 60 .

Проведенные механические испытания предлагаемых биметаллических наличников показали, что наплавленный слой обладает высокими прочностными свойствами и имеет износостойкость не ниже, чем у типовых наличников из стали $60 Г$.

\section{ЛИТЕРАТУРА}

1. Бабенко, Э. Г. К вопросу применения керамических флюсов на основе минеральных концентратов для восстановления деталей подвижного состава / Э. Г. Бабенко, Е. Н. Кузьмичев, Я. А. Новачук // Известия Транссиба. - 2012. - № 3(11).

2. Верхотуров, А. Д. Перспективные высоколегированные вольфрамом сплавы, полученные с использованием вольфрамсодержащего минерального сырья / А. Д. Верхотуров, Е. Н. Кузьмичев, Л. А. Коневцов // Ученые записки Комсомольского-на-Амуре государственного технического университета. - 2015. - № III-1 (23). - C. $74-80$.

3. Техническое обслуживание и ремонт локомотивов / под ред. В. А. Четвергова, В. И. Киселева. - М.: ГОУ «Учебно-методический центр по образованию на железнодорожном транспорте», 2007. - 558 с.

4. ЦТ-336. Инструкция по сварочным и наплавочным работам при ремонте тепловозов, электровозов и дизель-поездов. - М.: Транспорт, 1996. - 457 с. 
5. Сварочные материалы для дуговой сварки: в 2 т. Т. 1. Защитные газы и сварочные флюсы / Б. П. Конищев [и др.]; под общ. ред. Н. Н. Потапова. - М.: Машиностроение, 1989. - С. 268-269.

6. Пат. 2554049. Способ восстановления буксовых наличников рамы тележки железнодорожного подвижного состава / Е. А. Дроздов, Е. Н. Кузьмичев; опубл. 20.06.2015. Бюл. № 17.

7. Справочник сварщика / под общ. ред. В. В. Степанова. - М.: Машиностроение, 1983. - С. 560. 